\title{
Fibronectin-Enriched Biomaterials, Biofunctionalization, and Proactivity: A Review
}

\author{
Carla Palomino-Durand (1), Emmanuel Pauthe ${ }^{*,+}(\mathbb{D})$ and Adeline Gand ${ }^{*,+}$ \\ Equipe de Recherche sur les Relations Matrice Extracellulaire Cellules (ERRMECe), Institut des Matériaux, \\ CY Cergy-Paris Université, CEDEX, 95302 Cergy-Pontoise, France; carla.palomino-durand@cyu.fr \\ * Correspondence: emmanuel.pauthe@cyu.fr (E.P.); adeline.gand@cyu.fr (A.G.) \\ + A.G. \& E.P. contributed equally to the supervision of the contribution.
}

Citation: Palomino-Durand, C.; Pauthe, E.; Gand, A. FibronectinEnriched Biomaterials,

Biofunctionalization, and Proactivity: A Review. Appl. Sci. 2021, 11, 12111. https://doi.org/10.3390/ app112412111

Academic Editors: Barbara Nebe and Karine Anselme

Received: 10 November 2021 Accepted: 12 December 2021 Published: 19 December 2021

Publisher's Note: MDPI stays neutral with regard to jurisdictional claims in published maps and institutional affiliations.

Copyright: (c) 2021 by the authors. Licensee MDPI, Basel, Switzerland. This article is an open access article distributed under the terms and conditions of the Creative Commons Attribution (CC BY) license (https:// creativecommons.org/licenses/by/ $4.0 /)$.

\begin{abstract}
Modern innovation in reconstructive medicine implies the proposition of material-based strategies suitable for tissue repair and regeneration. The development of such systems necessitates the design of advanced materials and the control of their interactions with their surrounding cellular and molecular microenvironments. Biomaterials must actively engage cellular matter to direct and modulate biological responses at implant sites and beyond. Indeed, it is essential that a true dialogue exists between the implanted device and the cells. Biomaterial engineering implies the knowledge and control of cell fate considering the globality of the adhesion process, from initial cell attachment to differentiation. The extracellular matrix (ECM) represents a complex microenvironment able to meet these essential needs to establish a relationship between the material and the contacting cells. The ECM exhibits specific physical, chemical, and biochemical characteristics. Considering the complexity, heterogeneity, and versatility of ECM actors, fibronectin (Fn) has emerged among the ECM protagonists as the most pertinent representative key actor. The following review focuses on and synthesizes the research supporting the potential to use Fn in biomaterial functionalization to mimic the ECM and enhance cell-material interactions.
\end{abstract}

Keywords: fibronectin; extracellular matrix; biofunctionalized biomaterials; interfacial properties; surface coatings; hydrogels

\section{Introduction}

Facing the challenge of increasing needs for the reparation of the human body and emerging innovative strategies to realize the modern concepts of regenerative and reconstructive medicine, many medical devices have been proposed by the scientific community. These are used in a wide range of clinical applications, and their performance is highly dependent on the nature of their surfaces and the latter's interaction with defined proteins and cells.

Commonly, once a biomaterial is implanted, protein adsorption from biological fluids occurs immediately, mediating the interaction between the surface and cells. Concomitantly, a tissue reaction occurs, which results in an inflammatory response driven, largely by immune-related proteins and cell contact activation.

Although biomaterials were originally designed to be inert, contemporary applications, such as tissue engineering and regenerative medicine, demand biomaterials that can actively engage cellular matter to direct and modulate biological responses at implant sites and beyond [1-4]. Since biomaterials interact with their surroundings via their surfaces, an attractive strategy for producing truly bioactive materials is the design of biofunctionalized coatings. Of particular note are three-dimensional, cellularized, porous scaffold devices with interfaces optimized to support and implant viable cells, a promising breakthrough that will facilitate biomedical advances in the future. An appropriately modulated innate immune response would improve the acceptance of a given biomaterial by the host and its 
bio-integration with tissues. This principle is universal whatever the nature of the material, from metals and ceramics to polymers.

Currently, it is absolutely necessary to determine a way to promote a true and effective dialogue between the material and its cellular and tissular microenvironment. The notion of material-cell engineering has emerged, and it leads global, multifactorial, and complex cell behavior at the site of implantation. Throughout the overall cell-adhesion process, from the initial phase of the cell-contacting response (i.e., cell attachment) to later cell actions, such as differentiation, the different phases of a cell's fate must be taken into consideration.

This cell-material relationship is controlled and tuned by various parameters as following: (i) adhesion control influenced by physical characteristics such as the mechanical properties of the materials and their topography; (ii) chemical/biochemical molecular reactions mediated by the availability of growth-factor (GF) receptors, the actions of soluble factors, and the role of extracellular-matrix (ECM) protagonists.

The ECM is composed of fibrous protein polymers, typically type I collagen fiber networks, interspersed with strongly flexible and highly hydrated glycoproteins, polysaccharides, and other large molecules, from fibrin to heparin. Thus, there exist various molecular protagonists that, due to their specific and intrinsic properties, represent and respond to various concepts and needs.

Biomaterial engineering science necessitates a simple, pertinent, representative solution to elucidate this ECM. Among the ECM protagonists, considering the complexity, heterogeneity, and versatility of ECM actors, fibronectin (Fn) has emerged as the most pertinent key partner.

The aim of the following narrative review was to focus on the research supporting this crucial role of Fn in representing the ECM and to explore many of the versatile and predominant properties of biomaterials.

\section{Fn as a Pertinent Key Actor in the ECM}

The ECM, a material secreted by and surrounding cells, represents a complex network of polysaccharides (such as proteoglycans) and proteins (such as collagen, elastin, and Fn). This physical barrier delimits organs and represents the structural component of tissues that influences their development and physiology. Fn plays a major role in the ECM and is involved in numerous physiological processes, especially owing to its modular structure and the numerous properties of its different regions.

\subsection{Fn's General Properties}

Fn is a multifunctional glycoprotein expressed by many different cell types (hepatocytes, fibroblasts, macrophages, and leukocytes, among others). It is found in the plasma and the ECM. Its main biological functions are based on its affinity for different biological compounds such as cell-surface receptors, ECM proteins (collagens, heparin, etc.), DNA, gangliosides, and immunoglobulins [5].

In vivo, Fn mediates cell adhesion to the ECM and contributes to phagocytosis regulation, wound healing, cell proliferation, differentiation, and locomotion [6]. At the structural level, Fn is composed of two identical polypeptide subunits covalently linked via two disulfide bonds near their carboxy termini. Each subunit contains nearly 2500 amino acids (with a molecular weight of approximately 250,000 Da). It consists of a repetition of 56 modules of three types having a well-defined structure and a high degree of internal homology. Modules of types I, II, and III consist of 45, 60, and 90 amino acids, respectively. Type I modules make up the $\mathrm{NH}_{2}$-terminal and $\mathrm{COOH}$-terminal ends of the polypeptide. Two type II modules interrupt a row of nine type I modules at the $\mathrm{NH}_{2}$-terminus. Fifteen type III modules make up the middle of the polypeptide [7] (Figure 1A). Type I, II, and III modules are also found in many other proteins, with type III even being ubiquitous in animal proteins [8]. These modules are connected by short polypeptide segments sensitive to proteinases and are grouped into functional domains that express specific binding ac- 
tivities [9]. The above structure of Fn varies, depending on the cell source of the protein.

These variations are mainly due to the alternative splicing of the Fn mRNA [10].

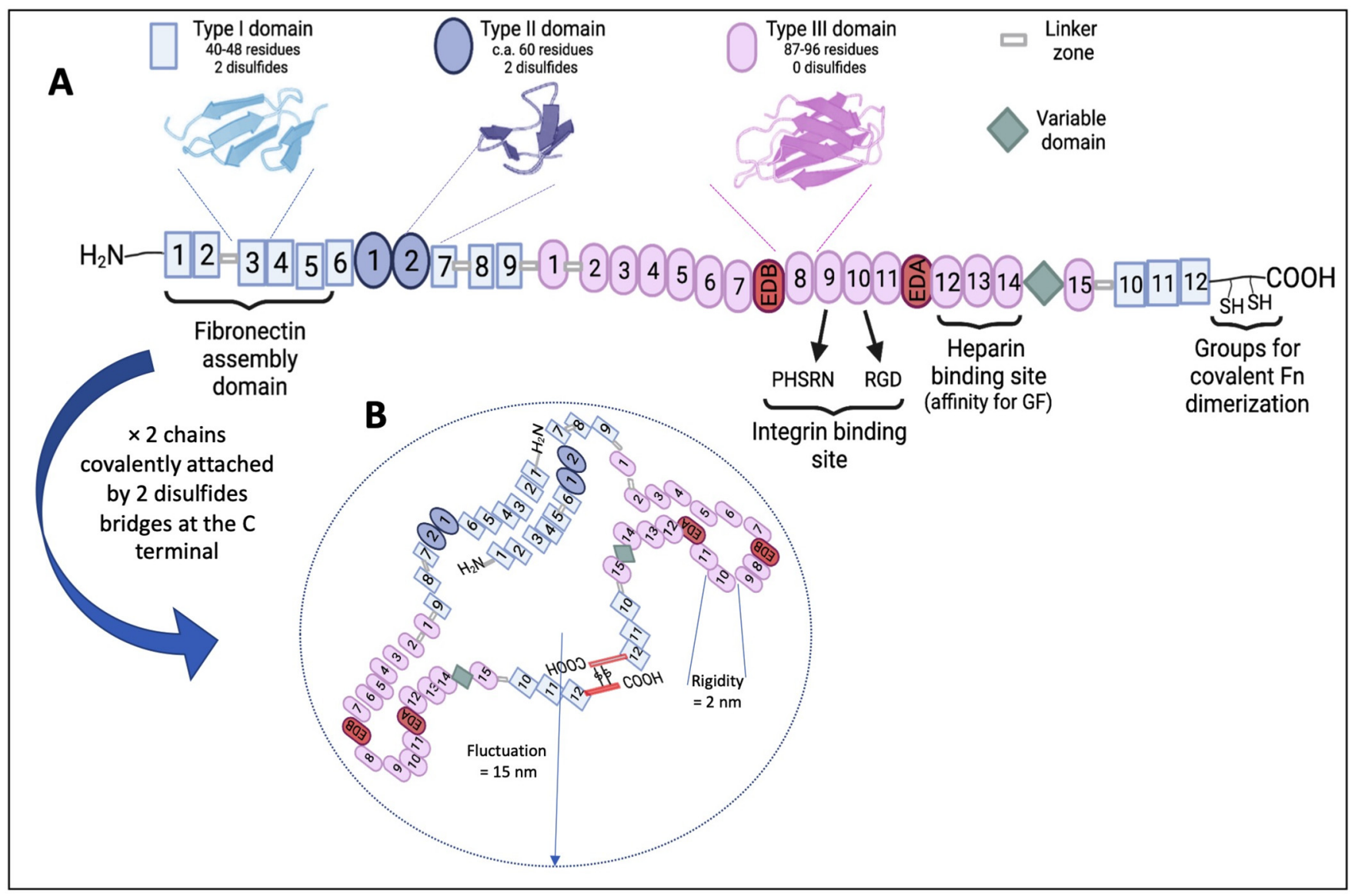

Figure 1. (A) Schematic representation of the modular composition of a fibronectin (Fn) chain. Type I, II, and III domains are depicted in light blue, purple, and pink, respectively. Upper: representative molecular model view of the $\beta$-sheet's secondary structural elements involved in the three different domains. The variable domain and extra domains A (EDA) and B (EDB) are indicated in green and red, respectively. Above: from left to the right, the brackets show the Fn assembly domain at the N-terminus, the integrin- and heparin-binding site in the central cell-binding domain, and sulfhydryl groups for covalent Fn dimerization at the C-terminus. (B) Representative view of the volume occupied by the dimeric soluble compact Fn in a solution.

The three types of modules are globular. Separately, their structures are known as being mainly $\beta$-sheet based on X-ray and NMR studies on isolated modules. Figure 1A provides the detailed information of this organization with several illustrations of the representative structural secondary elements found in the different modules [11-13].

The global conformation of Fn cannot be assumed from the folding of the individual isolated modules. No success in the crystallization of the whole protein has been reported. To understand the relationship between the Fn's structure and its various adhesive biological functions, several studies have been performed in solution. Fluorescence studies on the overall protein have shown the existence of hydrophobic domains $[14,15]$. Circular dichroism and infrared spectroscopy studies have only detected $\beta$-sheet secondary structures [15-17]. These results suggest that the modules within the overall protein retain the same structure as those that are isolated.

The conformation of the whole Fn in physiological conditions is debated and controversial. In 2000, in "native" conditions, through quasi-elastic light and small-angle neutron scattering studies, the radius of gyration $(\mathrm{Rg})$ of $15.3 \pm 0.3 \mathrm{~nm}$ and the hydrodynamic radius $(\mathrm{RH})$ of $11.5 \pm 0.1 \mathrm{~nm}$ were determined. These results imply a low internal concen- 
tration $\left(\mathrm{M} / \mathrm{R}^{3} \mathrm{~g} / \mathrm{H}\right)$ compared to those of the usual globular proteins. This is also confirmed by the $\mathrm{RH} / \mathrm{Rg}$ ratio of $0.75 \pm 0.02$, consistent with a Gaussian chain, whereas the $\mathrm{RH} / \mathrm{Rg}$ ratio of 1.3 was identified for spherical-shaped molecules. However, adding a denaturing agent ( $8 \mathrm{M}$ urea) increases Rg by a factor of two. This means that the Fn "native" chain is not completely unfolded. The average shape of the Fn conformation was also probed by small-angle neutron scattering performed for a reverse scattering vector q-1 smaller than $\operatorname{Rg}(0.2<\mathrm{q}-1<15 \mathrm{~nm})$. The measured form factor is in complete agreement with the form factor of a random string of 56 beads with $5 \mathrm{~nm}$ in diameter (Figure 1B). It rules out the possibility of an unfolded chain as well as globular structures [18]. This study demonstrates not only the complexity, but also the versatility offered by Fn in modulating and adapting its structural and conformational organization. In other words, considering the nature of $\mathrm{Fn}$, it is crucial to make a distinction between structure and conformation and to deal with the two definitions to clearly explain and discuss some specificity. For instance, conformation is used more to refer to the overall global whole-chain organization, whereas the structural level concerns the intrinsic remarkable structural elements in the modules. For example, without compromising the presence of the $\beta$-sheet in the individual modules, which provides the structure of the modules, the overall Fn molecule can transition from a highly extended and almost linear conformation to a globular and compact state. In other words, the molecule appears as a highly flexible and extendable string of beads capable of large conformational modulations.

Moreover, the global molecular organization of the whole Fn, at interfaces versus in solutions, is under control and mediated by the specificity and the nature (hydrophobic, charged, etc.) of the elements found along the chain.

First, the beta structures found in the three types of modules are composed of hydrophobic and large amino acids (Figure 1A). The structures of these apolar and hydrophobic elements are strongly influenced by polar or apolar environments, which, in turn, strongly impact the Fn's structure and its subsequent organization. The nature of certain solvents and the physicochemical properties of materials strongly affect the overall conformation and structure of the Fn [19].

Second, the charges of the different modules and the subsequent electrostatic effects also play a crucial role in the structuration and conformation of the molecule. The complete amino acid sequence of human Fn has been known for decades [20]. The protein data bank contains a specific amino acid sequence for the 32 modules of each chain. The attribution of one positive charge for arginine and lysine residues and one negative charge for aspartic acid and glutamic acid residues gives 192 positive charges and 259 negative charges, forming an overall net charge per chain equal to $-259+192=-67$. With more than 450 negative and positive residues charged among 2500, Fn is a true polyelectrolyte. Moreover, with $134(67 \times 2)$ more negative charges than positive ones, Fn, owing to this excess of negative charges, can be globally considered a polyanion. At a more detailed level, a fine analysis of the contained positively charged residues in each module, compared to the quantity of negatively charges, permits the calculation of the net charge for each module. The differences range between -11 (for the III-2 and the EDA modules with $-14 /+3$ and $-17 /+6$, respectively) and +6 (for the III- 14 with $-7 /+13$ ) (see Figure $2 \mathrm{~A}$ ).

This heterogeneous repartition of charges toward the different modules, precisely in the cell-binding region (the middle of the chain that contains the type III modules), gives rise, led by electrostatic interactions, to the specific folding of the chain in solution (Figure 2A). Moreover, the other part of the chains also adopts a specific orientation. The $\mathrm{N}$-terminal part must present a favorable orientation of the Fn assembly domain, which allows the stabilization of the globular conformation of the dimer. At the C-terminal part, the orientation of this segment is led by the constraint of the double disulfide cross-links that covalently binds the two Fn chains (Figure 2B). This "natural" folding and orientation of the chains is conserved and stabilized in the dimer structure (Figure 2C). 


\section{A}

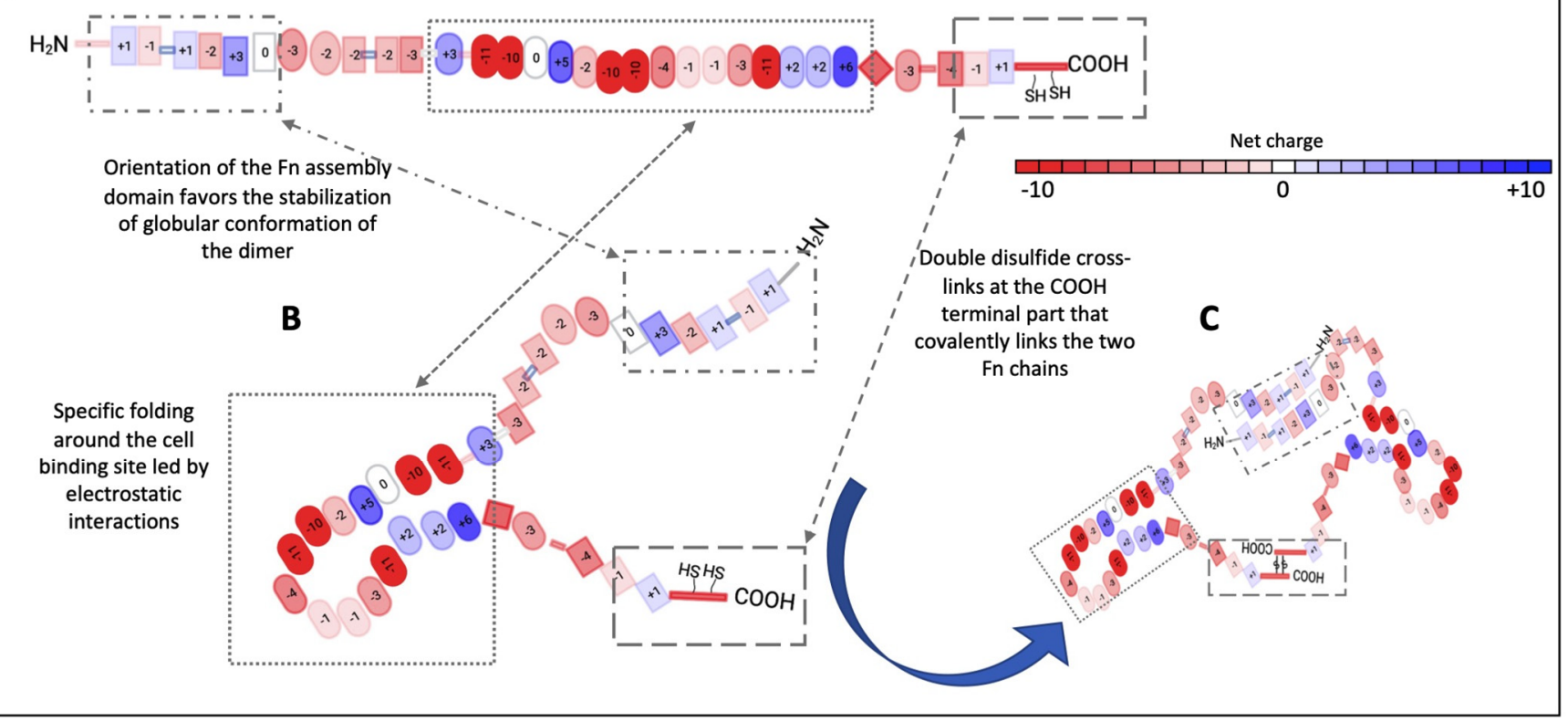

Figure 2. (A) Representation of the modular composition of an Fn chain with details of the electrostatic net charge for each of individual 32 domains. A red-blue scale illustrates the gradual change in the charge from -11 to +11 . (B) Schematic representation of the structural organization adopted by the chain in solutions, essentially mediated by electrostatic domain interactions in the type III-1-III-14 central domains. (C) Representation of an Fn dimer stabilized by disulfide cross-links at the C-terminus and Fn-Fn interactions in the N-terminal domain.

\subsection{Fn's Role and the Structure-Function Relationship within the ECM and Cells}

Cells' behaviors are under the control of their interactions with their surrounding extracellular microenvironment. Cells are very sensitive to the mechanical and biophysicochemical properties of this ECM environment, and cell receptors and integrins are mainly solicited. Via the integrins, cells literally "feel" the specificity of their environment and respond to crucial parameters such as mechanical properties. For instance, a lack of rigidity, as in a very soft environment, compromises cell adhesion and, subsequently, induces a lack of intracellular tension and non-performant intrinsic signaling pathway. Conversely, the ECM that presents a relatively high stiffness plays a pivotal role in provoking appropriate cell behaviors such as correct differentiation, the generation of intrinsic signals, the leading of focal adhesions and, thus, cell engagement in appropriate signaling pathways.

Moreover, in addition to the fact that cells respond to their biochemical environments via integrins, they also mainly employ GF receptors. Indeed, GFs, delivered to cells, are essential factors that govern part of their response. These GFs must be delivered specifically to the cells. In physiological conditions, they are present throughout the ECM, where they bind to the GF receptors.

When scientists and engineers design and generate biomaterials with interfacial properties capable of controlling cell behavior, it is of crucial interest to implicate and mobilize specific receptors' integrins and GF receptors, respectively. In other words, ECM models must consider both integrins and GF receptors. Moreover, integrins mediate adhesion related to the mechanical or viscoelastic properties of the environment. The ECM presents dynamic viscoelasticity, and biomaterials developed by engineers must also integrate these viscoelastic properties.

Thus, there are two crucial questions regarding the aim of satisfying and optimizing the dialogue between cells and their surrounding environments: (i) How do cells sense this viscoelasticity, and how can this viscoelasticity be incorporated into materials? (ii) How can GFs' presentation and their accessibility be maximized? Dalby et al., in a recent review, synthetized the different possibilities for presenting GFs [21], from uploading GFs in 
interfacial films to increasing GFs' affinity, specific chemical binding, or affinity in the ECM. Among these strategies, the development of materials with both integrin binding and GF binding represents a highly interesting way to solve these problems.

Fn appears to be the most pertinent protagonist of the ECM for satisfying the latest requirements and addressing this interesting dual specificity. First, as presented above, among the different modules that contain specific properties, the modules III-10 and III-9 contain the well-known RGD and PHSRN sequences that are, highly specific and a wellknown region for integrin binding, respectively (especially $\alpha \mathrm{v} \beta 3$ and $\alpha 5 \beta 1$ ). Second, in the vicinity of this region, there exists a row of three specific type III modules (III-12-III-14 heparin-binding site) that exhibit a specific affinity for binding GFs (Figure 1A). Martino and Hubbell showed that Fn III-12-III-14 from Fn promote the binding of GFs including BMP2 [22]. Thus, within Fn, integrin binding can be simultaneously optimized with GF binding.

The accessibility of these regions necessitates a specific Fn dynamic conformation and structural rearrangement. Initially secreted from cells and, in solution, organized as a compressed, soluble dimer connected by disulfide linkages, Fn is naturally stimulated in an active state by interactions between its integrin-affinity sequences and synergy domains of the integrin present on the cell surface. This initiates a gathering of several Fn molecules near the cell surface. Although each molecule has a row of five Fn-specific binding sites, the primary matrix-assembly domain, located near the disulfide bonds, is essential for fiber formation. The high concentration of activated Fn molecules promotes the linkages between each of these and molecules from surrounding cells. The process generates a network of interconnected, stabilized, and insoluble proteins connecting cells throughout the matrix (Figure 3).

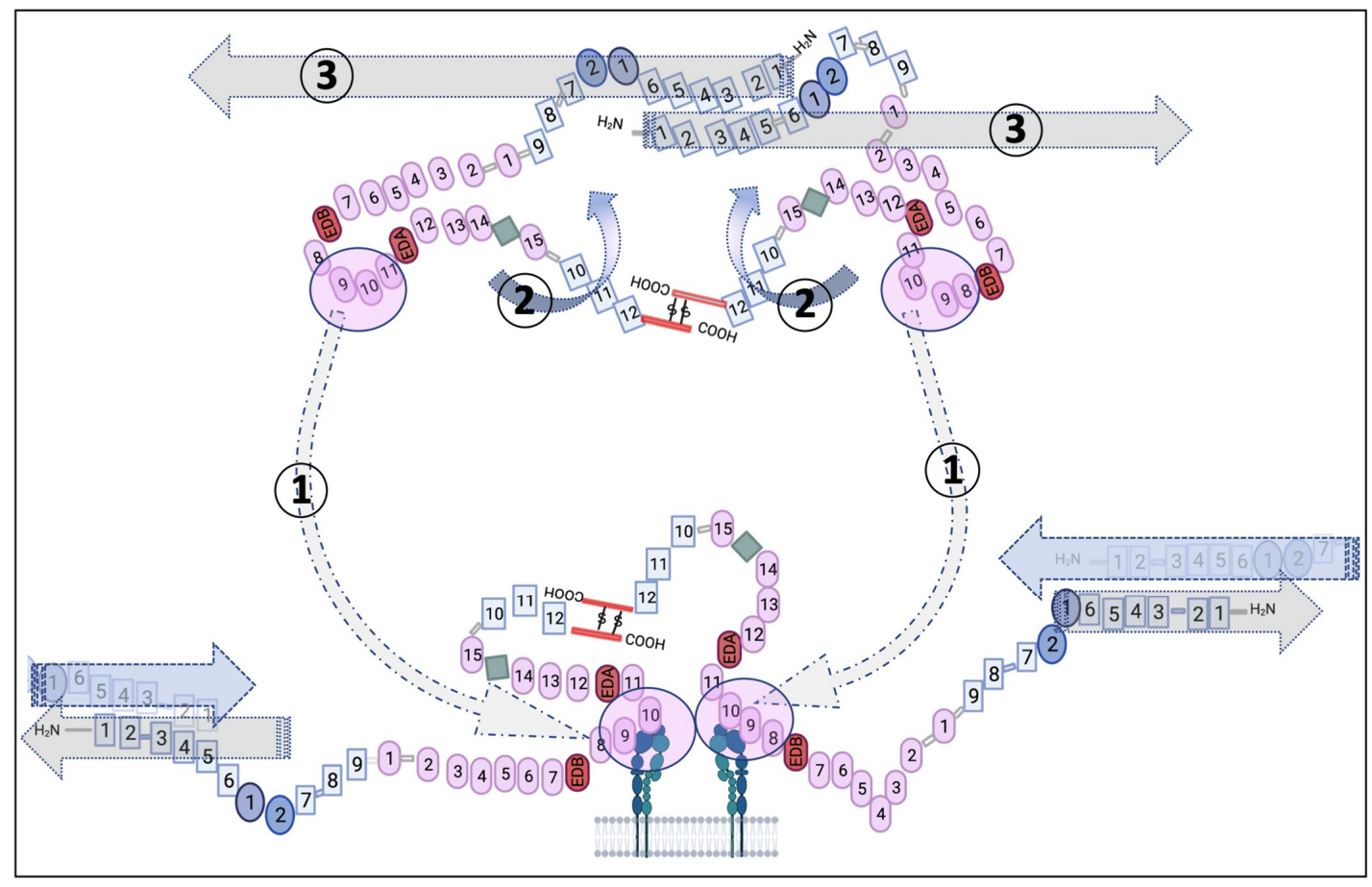

Figure 3. Schematic representation of the major steps that mediate an Fn fibrillar assembly at the interfaces and lead to a structural Fn reorganization from a soluble compact form to aligned Fn molecules with fibrils. First, the III-9 and III-10 modules of each chain of the soluble Fn bind to the integrins clustered at the surface (1). This triggers a reorganization of both the type III modules around the cell-binding domain and that of the disulfide bridge cross-links at the C-terminal part of each chain in a double-folded loop orientated to face the integrins and a dissociation of the N-terminal dimer assembly with a motion of the row of the six type I modules at the N-terminal site that now become aligned in parallel to the membrane, opposite to the orientation in a solution (2). This opening and new orientation of the N-terminal Fn-assembly domain favors interactions with the N-terminal domain of another Fn molecule and, consequently, initiates Fn fibrillogenesis (3). 


\section{Fn Application and Involvement in Biomaterials and Medical Device Engineering}

As already established, one of the main challenges in material implantation is appropriate bio-integration that conditions the successful performance of the implant in the human body. Implant-host tissue crosstalk must be improved through interfacial strategies. In recent years, there has been increasing interest in the functionalization of surfaces with protein coatings, since the first event to occur right after implantation is the interaction between the implant and circulating blood components, leading to the adsorption of ECM proteins. Consequently, cells do not interact directly with the implant but interact with protein coatings [23] that influence cell behavior (recruitment, adhesion, and differentiation). In this context, proteins from the ECM are of particular interest. As described above, due to its intrinsic biochemical properties and specific biophysical multi-modular structuration, Fn plays a key role in mediating cell behavior, from adhesion, growth, and migration to differentiation.

Many studies have described strategies based on the selection of a discriminant part of Fn. For instance, studies report the extensive use of functional fragments of Fn, such as specific Fn peptides or moieties containing integrin-binding domains (RGD and PHSRN), to improve implant integration [24-26]. Despite numerous opportunities, these strategies present drawbacks due to the lack of synergy and cooperation between different modules.

A full-length Fn protein, instead of small peptides, could provide secondary actions linked to the presence of other binding sites, and it is more biomimetic of the ECM and also fully integrates the dimension of the protein dynamic which is essential for representing the structural molecular rearrangement involved during the remodeling of the cell microenvironment.

Different strategies can be used to functionalize materials with Fn:

- Simple molecular two-dimensional (2D) coatings at interfaces via covalent binding or adsorption and the use of aptamers to favor Fn adsorption in monolayers;

- Complex coated interfaces, where Fn is combined with other molecules in order to form bioengineered multilayered interfaces generating thin films and interfaces in 2.5D;

- Fn distribution in a three-dimensional (3D) volume entrapped in hydrogels via physical dispersion and covalent cross-linking.

These biofunctionalized interfaces recreate, at different levels, various pertinent and representative biomimetic cell microenvironments between the implant and the surrounding tissues.

\subsection{Fn 2D Molecular Coatings \\ 3.1.1. Fn Covalent Binding}

The covalent binding of Fn presents many advantages such as the strong and stable linkage of molecules to the surface. Nevertheless, the grafting process is delicate, as it should proceed in mild conditions to preserve the protein structure and requires the presence of functional groups at the surface of the biomaterial able to react with reactive protein groups, which often requires a preliminary activation step at the surface. The following section describes the main published papers regarding surface activation and Fn-grafting modes on various substrates, which are summarized in Table 1. 
Table 1. Fn surface functionalization of different substrates using different strategies and related biological activities.

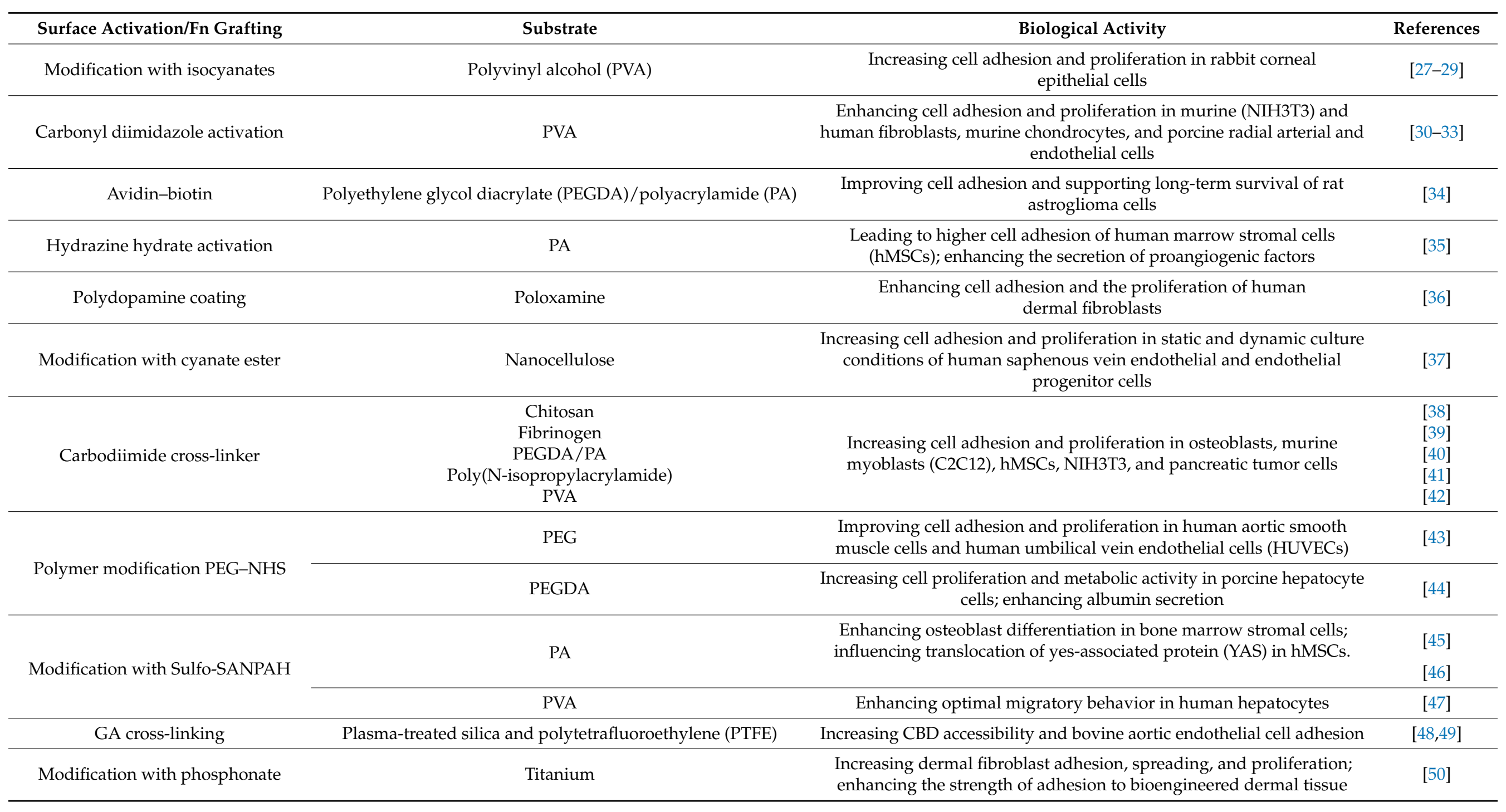


One of the first approaches to Fn-covalent immobilization was reported by Kobayashi and Ikacia on polyvinyl alcohol (PVA) hydrogels for contact lens applications [29]. In this case, PVA, known to be a highly bio-inactive polymer, was modified by the addition of isocyanate groups able to react with the amino and hydroxyl groups of Fn to form urea and urethane bonds, respectively [29]. The resulting Fn-functionalized PVA enhanced the adhesion of corneal epithelial cells and their proliferation $[27,28]$. PVA chains can also be activated via a three-step reaction: the linkage of alkyl chains containing acids group followed by acid-group activation with carbonyl diimidazole (CDI) and, finally, a PVACDI reaction with Fn amine groups [30-33]. This Fn-covalent-grafting strategy permits the obtention of a normal cell morphology, higher cell adhesion, and the proliferation of NIH3T3 fibroblast cells [30], primary human foreskin fibroblasts [31], chondrocytes [32], and porcine radial arterial and endothelial cells [33].

Other strategies for Fn covalent immobilization on hydrogel surfaces using an avidinbiotin-binding system have also been described in the literature [34], as have those involving surface activation with hydrazine hydrate [35] or via a polydopamine-coating process [36]. Recently, Wacker et al. reported the biofunctionalization of bacterial nanocellulosehydrogel-based vascular grafts (BNCs) with human albumin, Fn, or heparin-chitosan [37]. Briefly, BCN surfaces were activated with 1-cyano-4-dimethylamino pyridinium tetrafluoroborate (CDAP). Bioconjugation with proteins was induced by the formation of isourea bonds with amino acids. The Fn bioactivity regarding human saphenous vein endothelial cell (VEC) and endothelial progenitor cell (EPC) adhesion and proliferation was remarkable compared to that of albumin or heparin coatings [37].

The grafting processes described above remain difficult to implement, as they involve many complex steps. Therefore, Custodio et al. developed a simple and low-cost method for the immobilization of Fn on chitosan using N-(3-dimethylaminopropyl)-N'ethylcarbodiimide (EDC) as a cross-linker [38]. They showed that human-osteoblast-like cell adhesion is promoted on chitosan functionalized with immobilized Fn and that the long-term proliferation of cells is enhanced compared to that on surfaces with adsorbed Fn. On the contrary, adsorbed Fn has been shown to desorb over time, as only weak and unspecific forces are involved in the protein's immobilization on the surface (hydrogen bonds, Van der Waals forces, and electrostatic or hydrophobic interactions). This simple technique was successfully used to functionalize different hydrogel surfaces such as fibrinogen [39], polyethylene glycol diacrylate (PEGDA)/polyacrylamide (PA) [40], poly(Nisopropylacrylamide) [41], and PVA [42]. A homogeneous distribution of Fn on all surfaces and a good cell-hydrogel interaction via improved cell adhesion and proliferation has been highlighted.

Another similar and simple approach using N-hydroxy succinimide (NHS) to covalently attach Fn has also been described. The cross-linking between the NHS-ester of modified PEG-NHS and free amino groups on Fn has also been reported $[43,44]$. Shinoara et al. demonstrated a better cell adhesion and proliferation of human fetal lung fibroblasts, human aortic smooth muscle cells (HASMCs), and human aortic endothelial cells (HAECs) in a PEG-Fn hydrogel compared to that in a bare PEG hydrogel or PEG-gelatin hydrogel [43]. Recently, the modification of a hydrogel surface with sulfo-SANPAH (a molecule containing an NHS-ester and a photoactivatable nitrophenyl azide) to cross-link Fn has been reported [45-47]. Stanton et al. showed the biofunctionalization of a PA hydrogel surface with ECM proteins such as Fn, type I collagen, type IV collagen, and laminin using sulfo-SANPAH. They reported that Fn and laminin biofunctionalization results in a more homogeneous distribution than collagen type I or IV, using immunostaining. Moreover, the quantity of Fn immobilized at the surface is higher than those for other ECM proteins [46].

The covalent binding of Fn to the surface can affect Fn's conformation and, thus, bioactivity. Vallières et al. showed that Fn can be anchored via its lysyl or cysteyl moieties on a PTFE or silica treated with ammonia plasma via two conjugation strategies using glutaric anhydride (GA) and sulfosuccinimidyl 4-(p-maleimidophenyl) butyrate (SMPB) cross- 
linking agents. They showed that Fn adopts different conformations and that the covalent binding of Fn via its lysyl group is more favorable for cell adhesion [48,49]. A recent study showed that the hydrophilic/hydrophobic nature of the linker, its length, and the binding site on the protein influenced the Fn conformation and RGD accessibility [51]. Fn grafting has also been used to functionalize titanium surfaces in the context of transcutaneous implants to enhance soft-tissue sealing around the implant [50]. In this study, the authors showed that Fn grafted via phosphonate-linking arms increases dermal fibroblast adhesion, spreading and proliferation, and the strength of the adhesion between the functionalized material and the bioengineered dermal tissue.

Even if the covalent binding of proteins leads to stable surfaces and locks the protein in a defined conformation, the grafting process remains difficult and involves many steps, and it remains difficult to control the protein's conformation and, therefore, to maintain its bioactivity.

\subsubsection{Fn Physical Adsorption}

Physical adsorption can lead to unstable coatings; however, it is less damaging for the conformation of the adsorbed molecules. Zhang et al. investigated the bioactivity of adsorbed Fn vs. Fn covalently immobilized on polyethylene terephthalate (PET) [52]. They showed that adsorbed Fn results in higher accessibility for the RGD domain and bioactivity. Over the last few decades, Fn adsorption on various biomaterial surfaces has been analyzed and garnered great interest in different contexts.

The overall surface properties of a biomaterial, such as the chemical composition, topography and roughness, hydrophobicity, and surface energy, influence the adsorption, structure, and function of proteins and have impacts on cell responses [53-55]. Several studies have shown the influence of surface topography on Fn adsorption. Microtopography leads to a heterogeneous adsorption of the protein: on rough or micro-grooved surfaces, Fn is preferentially adsorbed on peaks or onto groove/ridge boundaries [56,57]. Nanostructures at the surface also influence the amount of Fn adsorbed, but in this case, a homogeneous deposition of 10-20 $\mu \mathrm{g} / \mathrm{mL}$ Fn solution has been observed [58]. In all cases, great impacts on cell spreading, adhesion, and the size of focal adhesion have been observed.

Interactions between Fn and polymeric surfaces have been demonstrated to be influenced by surface hydrophobicity. Early studies revealed that the amount of Fn adsorbed on hydrophobic surfaces is higher, but the protein is less active [59,60]. The loss of Fn's bioactivity could be directly linked to Fn's conformation: on a hydrophilic substrate, atomic force microscopy (AFM) images highlighted an elongated conformation of Fn and, thus, the exposure of specific binding sequences were obtained, whereas on hydrophobic substrates, a more compact structure was observed [61]. Baujard-Lamotte et al. also demonstrated that, even though the surface densities of Fn adsorbed onto a hydrophilic silica surface and a hydrophobic polystyrene surface are identical, Fn retains a native conformation on the hydrophilic substrate while exhibiting an alteration of the globular module on the hydrophobic material [19]. To assess the impact of surface chemistry on Fn adsorption and conformation, self-assembled monolayers presenting different terminated groups were used as model surfaces. Fn adsorption on gold surfaces modified by self-assembled monolayers (SAMs) of alkanethiols terminated with $\mathrm{CH}_{3}, \mathrm{OH}, \mathrm{COOH}$, and $\mathrm{NH}_{2}$ functionalities led to differences in the accessibility of the integrin-binding domain [62] and, therefore, had a direct impact on cell adhesion and spreading, with higher cell responses on $\mathrm{OH}-$ SAMs [54]. Protein conformation and integrin-binding site accessibility play key roles in early cell adhesion; however, Lin et al. showed that the force of protein adsorption on a biomaterial and protein reorganization carried out by cells affect long-term cell adhesion and are directly related to surface chemistry [63].

Recently, surfaces exhibiting a specific chemistry—poly(ethyl acrylate) (PEA)—have been shown to induce Fn fibrillogenesis, a process usually driven by cells, leading to the formation of a physiological fibrillar network $[64,65]$. On these surfaces, Fn adsorbs in a 
conformation that permits the simultaneous exposure of the integrin-binding domain (Fn III-9 and -10) and GF-binding domain (Fn III-12-III-14), leading to a synergistic presentation of the GFs BMP2 and VEGF for bone regeneration or vascularization $[66,67]$.

Biomaterial biofunctionalization with Fn is often used to enhance implant biointegration and biocompatibility, modulating the cell response. Fn adsorption on biomaterials has also been shown to modulate the inflammatory and wound-healing process that occurs after biomaterial implantation. Monocytes adhere to the material surface rapidly after implantation and become activated macrophages able to release proinflammatory cytokines [68]. Shen et al. showed that Fn adsorption on TCPS increases monocyte adhesion, but the release of the proinflammatory cytokine TNF $\alpha$ and the level of foreign body giant cell formation are lower compared to those for TCPS coated with IgG [69]. Fn coatings on specific polyurethanes were also explored in the context of vascular applications. The results showed that the specific cell-binding sequences of the Fn are less exposed to cell receptors that could reduce the immune cell response and inflammation [70].

To enrich biomaterial surfaces with Fn, another strategy consists of the use of aptamers to enhance Fn retention. Aptamers are small single-stranded oligonucleotides that overcome a specific and defined 3D conformation and specifically bind a target molecule. They are thus good candidates for therapeutic purposes in the same way as antibodies but without their disadvantages, which are their immunogenicity and low stability [71]. The functionalization of biomaterials with aptamers could thus control the adsorption of proteins that occurs shortly after implantation by selectively binding a target protein. Parisi et al. used aptamers directed against Fn to promote the specific adsorption of the protein and to enhance the cell colonization of chitosan films. They showed that the use of aptamers had no influence on the amount of Fn adsorbed on the surface but improved osteoblastic and human epithelial cell adhesion, proliferation, and spreading [72,73]. Aptamers thus help to maintain Fn in a functional conformation that enhances the cell response at the interface.

To obtain multifunctional coatings, Fn can also be co-immobilized with other molecules. In the context of cardiovascular implants, for a family of biomaterials in direct contact with blood, the main issues are long-term implantation and implant failure due to thrombus formation and the absence of endothelialization. Fn is co-adsorbed or co-immobilized on a fluorocarbon polymer or titanium in association with phosphorylcholine or heparin, known for their antithrombogenic and anticoagulant properties. It has been shown that the association of Fn with these molecules could improve the endothelialization process and prevent thrombus formation $[74,75]$. Fn can also be co-adsorbed with plasma proteins and generate a synergetic effect. This is the case, when Fn is co-adsorbed with albumin; the association of the two proteins modulates preosteoblastic cell adhesion, spreading, and proliferation and may enhance fibroblast adhesion [76-78].

\subsection{Fn in Complex Coated Interfaces}

Surface biofunctionalization can occur via Fn 2D simple coatings, but increasingly, studies have focused on complex interfaces in order to form bioengineered interfaces. In the context of biomedical applications, coatings formed by layer-by-layer (LbL) assemblies are of growing interest due to their high versatility [79]. This technique is based on the alternate deposition of oppositely charged polyelectrolytes [80], which results in the formation of thin coatings, ranging from a few nanometers to a few microns, which are easy to fabricate and can be deposited on any type of surface irrespective of their geometry and chemistry, making them attractive for implant functionalization. Thin films properties can be easily modulated in terms of thickness, rigidity, and roughness and can be functionalized with bioactive molecules or serve as reservoirs for the controlled delivery of biomolecules [81-86]. Fn can be considered a polyampholyte with negatively and positively charged patches and an acidic isoelectric point (5.5-6) (Figure 2). It is thus negatively charged at physiological $\mathrm{pH}$ and can be used as a polyanion to functionalize the surfaces of polyelectrolyte multilayer films or directly incorporated during film assembly. 
Polyelectrolyte multilayer films often present low mechanical rigidity, which is not favorable for cell adhesion and spreading. To overcome this drawback, several authors decided to functionalize an LbL film with Fn adsorbed on top of the film. Wittmer et al. showed that it is possible to adsorb Fn as a top layer on a poly-L-lysine (PLL) (+)/dextran sulfate $(-)$ nanofilm and that it positively affects cell spreading [87]. They noted that the charge of the terminated layer could influence Fn adsorption, with a higher amount of protein adsorbed on films exhibiting a positively charged terminated layer. Surprisingly, it is also possible to adsorb Fn on poly(sodium 4-styrenesulfonate) (PSS) in a higher amount than on non-functionalized surfaces.

The nature of the terminated layer, thus, has an impact on Fn adsorption and could also impact the protein conformation. Ngankam et al. studied the adsorption of Fn on PSS $(-)$ and poly(allylamine hydrochloride) (PAH, $(+))$ thin films. They found that, on PAHterminated films, the Fn adsorption, density, and thickness are higher than those on a PSSterminated layer. However, integrin-binding sites are more accessible on PSS-terminated thin films, suggesting a potential higher bioactivity [88]. It has been clearly shown that the adsorption of an Fn monolayer on the top of thin films positively influences cell adhesion and spreading $[87,89,90]$; the properties of the underlying thin films (i.e., thickness and roughness) are also of great importance [90].

Recently, hybrid cell adhesive materials (hCAMs) have been developed where a bilayer of Fn and PAH is deposited on top of polyelectrolyte multilayer films. hCAMs allow the long-term anchorage of P19 cells, and pluripotent cells are able to differentiate into neuronal skeletal muscle and cardiac muscle. Their proliferation and differentiation into neuron-like cells have been studied under dielectrophoretic conditions and continuous fluid flow [91]. hCAM constructs have also been used to develop an in vitro model to study tumor-endothelial cell interactions. The co-culture of hepatocarcinoma cells (HepG2) and endothelial cells (HUVECs) on hCAMs shows that HepG2 tends to form 3D structures while endothelial cells form cords [92]. When hCAMs are treated with transglutaminase, known to play a role in the cross-linking of ECM proteins, Hep2G cells change from $3 \mathrm{D}$ to $2 \mathrm{D}$ morphology, suggesting that Fn remodeling plays a key role in $3 \mathrm{D}$ structure morphology formation.

Fn has also been directly integrated in polyelectrolyte multilayer films during film assembly in place of an anionic polyelectrolyte in order to generate interfaces biomimetic of the ECM. Enriched-Fn thin-film construction in association with PLL or collagen follows a novel growth regime, as the film seems to stall after a few layers, whereas polyelectrolyte multilayer films usually adopt linear or exponential growth $[93,94]$. Nevertheless, film assembly includes proteins that are non-trivial and is highly influenced by the construction conditions, i.e., type of buffer and $\mathrm{pH}$. Fn-based multilayer thin films (PLL-Fn) 5 are able to enhance murine MC3T3-E1 preosteoblastic cell adhesion, spreading and proliferation compared to an Fn monolayer. Cells can reorganize Fn into fibrils, and after seven days of culture, Fn remains in a thin film. Thin films enriched in Fn, therefore, constitute a reservoir of Fn, which is able to be used and remodeled by cells, thereby improving cell proliferation [93].

Finally, LbL assembly can also be performed on the cell surface to protect and control cell function $[95,96]$. Fn in association with gelatin creates a protective barrier around cells in a stressful environment, and the protection is greater with Fn-gelatin thin films than with films constructed with synthetic polyelectrolytes, the protection being directly dependent on the thickness of the film [96].

\subsection{Fn in Volume}

Hydrogels are 3D polymeric networks that can mimic some specific ECM characteristics due to their properties such as porosity, swelling, and viscoelasticity [97]. As 3D biomimetic artificial matrices, hydrogels must be tuned to favor appropriate cell behavior and to provide an appropriate microenvironment. There is thus a need for hydrogels to exhibit specific mechanical properties and appropriate biological cues [97,98]. Hydrogels 
could be obtained with different types of hydrophilic polymers (natural or synthetic). However, there may be some drawbacks, such as insufficient cell-anchorage cues, which can lead to minimal cell adhesion and spreading [99-101] or a decrease in cell viability in the case of cell encapsulation $[102,103]$.

As previously described, surface biofunctionalization with full-length Fn has been shown to greatly enhance cell-material interactions on substrates of various natures.

Fn can also been included within hydrogels to generate a 3D biomimetic matrix and realize ECM-like biological functions. Different strategies can be employed for Fn incorporation and entrapment within the 3D network, such as simple physical entrapment and/or covalent linking within the hydrogel's matrices. Numerous parameters and characteristics must be taken into consideration and tested. The nature of the polymers, from natural to synthetic ones, is of primary interest. Over the last few decades, following different aims and perspectives, numerous results have been obtained regarding the generation of the desired cell response related to desired applications, etc. The following section reports some of the most significant results obtained, summarized in Table 2, which show the synthesis of the published work classified according to the mechanism involved in Fn addition, i.e., physical dispersion or covalent cross-linking.

\subsubsection{Fn Physical Dispersion}

Some remarkable studies dealing with Fn physical dispersion have been reported for alginate-based hydrogels $[98,100,101,113]$. For instance, Mosahebi et al. investigated the addition of $\mathrm{Fn}$ in an alginate solution before physical gelation with $\mathrm{Ca}^{2+}$ and its impact on nerve regeneration. Schwann cells (SCs) were encapsulated in an alginate or alginate-Fn hydrogel. The alginate-Fn hydrogel appeared to clearly improve cell proliferation and metabolic activity. In vivo studies in a peripheral-nerve-injury model of SCs encapsulated in an alginate-Fn hydrogel demonstrated a steady progression of axons up to six weeks [100]. Interestingly, similar results were obtained by Novikova et al., with an increase in the metabolic activity of olfactory ensheathing cells and the improvement of neurite sprouting from dorsal root ganglion in an alginate-Fn hydrogel compared to that in a bare alginate hydrogel [101]. The differentiation of stem cells in alginate-Fn physical hydrogel beads has also been evaluated. Gilmozzi et al. described the differentiation of human-induced pluripotent stem cells (hiPSCs) to dopaminergic (DA) neurons. They showed higher cell viability for the long-term culture (20 days) of encapsulated hiPSCs in alginate-Fn hydrogel beads compared to alginate alone and an increase in the transcriptionfactor (i.e., LMX1A and FOXA2) expression of DA neurons over time [98]. The advantage of using this $3 \mathrm{D}$ culture system was demonstrated by the presence of synaptic connections formed by 3D neurons. An interpenetrating polymer network hydrogel composed of alginate/gelatin/hyaluronic acid polymers was fabricated through dual cross-linking with a temperature change and the addition of $\mathrm{Ca}^{2+}$ for a 3D impression [102]. Fn was added to the mixture before gelation, and chondrogenic progenitor cells (CPCs) were encapsulated into the hydrogel. Although the Fn was released from the hydrogels (a burst release within 8 days was observed, followed by a sustained release up to 14 days), the cells encapsulated in the Fn-functionalized hydrogel showed an increase in chondrogenic marker (COL2, PRG4, and SOX9) expression compared to those in a bare hydrogel [102].

The potential of using a collagen-based system was also explored. Several studies report Fn entrapped within collagen hydrogels [103,104,114,115]. For example, GonzalezPerez et al. investigated the regeneration of a critical sciatic nerve gap $(15 \mathrm{~mm})$ in rats. In this case, they compared the effect of the functionalization of laminin or Fn in a collagen type I hydrogel within chitosan conduits and showed an improvement in nerve regeneration in the collagen-Fn hydrogel [103]. Recently, Norris et al. evaluated the protein organization and biological activity of a collagen-Fn hydrogel using an ultrasound methodology. Fn was added to a neutralized collagen solution before ultrasound exposure at a constant frequency. A pattern of radially aligned collagen fibers with co-localized Fn was observed in the ultrasound-exposed samples. Fn-null mouse embryonic fibroblasts 
were seeded on top of these hydrogels, and the reorganization of Fn in fibrils was only observed in the ultrasound-exposed samples [104]. A composite collagen/gelatin hydrogel was biofunctionalized with Fn in order to improve the chemotactic and bioactive action on human apical papilla cells for dental-pulp regeneration [105]. The study showed that the entrapment of Fn at a concentration of $10 \mu \mathrm{g} / \mathrm{mL}$ promoted cell viability and cell migration through a membrane compared to the collagen/gelatin hydrogel alone. The higher gene expression of $\alpha 5$ integrin (ITGA5), $\alpha \mathrm{V}$ integrin (ITGV), type I collagen (COL1A1), and type III collagen (COL3A1) was also observed.

In other studies, a PEG-based system was considered. PEG-diacrylate (PEGDA) hydrogels were combined with natural polymers, such as collagen [106] and fibrinogen [107]. In these cases, Fn was physically entrapped within hydrogels to provide an appropriate 3D environment for stem cells. Nii et al. reported the encapsulation of human adipose-derived stem cells (hADSCs) in PEGDA-collagen hydrogels. They showed that the addition of a specific concentration of Fn $(10 \mu \mathrm{g} / \mathrm{mL})$ combined with an intermediate matrix stiffness $(\sim 55 \mathrm{kPa})$ led to cell differentiation into the osteoblastic phenotype associated with a significant increase in osteocalcin expression (130-fold) [106]. Furthermore, Goldshmid and Seliktar described the encapsulation of human mesenchymal stem cells (hMSCs) in a PEGDA-fibrinogen hydrogel. A combined addition of Fn and the Von Willebrand factor into the hydrogel (5\% and $2 \%$, respectively) resulted in higher cell proliferation and an improvement in cell pluripotency [107].

The results presented above demonstrate the potential of using simple physical links to foster the effects of Fn within hydrogels. However, some undesired effects, such as uncontrolled burst release and the instability of 3D systems, were frequently observed. This suggests that the better control of Fn stabilization inside the gel may represent a route for improving Fn-based 3D hydrogel applications. These considerations have pushed researchers to explore the drawbacks and opportunities of covalently immobilizing Fn inside hydrogels. Some of the major results are presented in the following section.

\subsubsection{Fn Covalent Cross-Linking}

Fn has been incorporated using different chemical cross-linking strategies in hydrogels made with natural compounds. First, for example, fibrin hydrogels containing Fn covalently cross-linked by factor XIII and thrombin have been reported [117]. Associated with vitronectin, fibrin-Fn hydrogels have been used as a platform to deliver autologous mesenchymal cells in an emphysema sheep model. The authors demonstrated the capacity of this system to promote tissue regeneration after four weeks [112]. Moreover, Ao et al. reported the benefit of using a fibrin-Fn hydrogel system to specifically bind heparin (Hep) and subsequently improve the presentation of bone morphogenic protein (BMP2) to cells. A fibrin/Fn/Hep-BMP2 hydrogel led to mineralization after 21 days of MC3T3 cell culture and the expression of osteogenic markers (ALP, RUNX2, OPN, OCN, and COL-I). In vivo tests in a rat calvaria critical-sized defect model revealed significantly improved bone regeneration compared to that achieved with a local administration of high-concentration BMP2 [113]. Complementary to the enzymatic natural cross-linking approach described above, other chemical strategies have been explored. For instance, the covalent immobilization of Fn inside hyaluronic acid hydrogels has been performed by a photopolymerization reaction. Seidlits et al. investigated this method for functionalizing hyaluronic acid hydrogels and showed that encapsulated HUVECs presented increased viability and migrated into aligned structures organized in tubule-like networks [101]. In addition, Trujillo et al. developed an HA hydrogel that contained Fn covalently cross-linked by thiolene addition mediated by photopolymerization. MSCs seeded on the top of or encapsulated in the HA-Fn hydrogel presented well-defined actin fibers and high cell adhesion compared to in the HA hydrogel [99]. 
Table 2. Fn in a three-dimensional (3D) matrix using different strategies and related biological activities.

\begin{tabular}{|c|c|c|c|c|}
\hline Type of Binding & Mechanism of Fn Addition & Polymer & Biological Activity & References \\
\hline \multirow{8}{*}{ Physical entrapment } & \multirow{8}{*}{ Dispersed into a hydrogel } & \multirow{2}{*}{ Alginate } & $\begin{array}{l}\text { Improving cell proliferation and metabolic activity in rat Schwann cells and } \\
\text { olfactory ensheathing cells; enhancing nerve reparation in vivo }\end{array}$ & {$[104,105]$} \\
\hline & & & $\begin{array}{l}\text { Increasing cell viability for the long-term culture of human induced } \\
\text { pluripotent stem cells (hiPSCs) and cell differentiation }\end{array}$ & [102] \\
\hline & & Alginate/gelatin/hyaluronic acid & $\begin{array}{l}\text { Enhancing the proliferation, migration, and chondrogenic differentiation of } \\
\text { rat chondrogenic progenitor cells }\end{array}$ & [106] \\
\hline & & \multirow[b]{2}{*}{ Collagen } & Improving nerve regeneration in adult rats & [107] \\
\hline & & & $\begin{array}{l}\text { Co-localizing and reorganizing Fn in fibrils after the seeding of } \\
\text { fibronectin-null mouse embryonic fibroblasts }\end{array}$ & [108] \\
\hline & & Collagen/gelatin & $\begin{array}{l}\text { Improving the adhesion, spreading, and viability and migration of human } \\
\text { apical papilla cells; gene expression of } \alpha 5 \text { integrin, } \alpha \mathrm{V} \text { integrin, and type I } \\
\text { and type III collagens }\end{array}$ & [109] \\
\hline & & Agarose & $\begin{array}{l}\text { Enhancing cell survival, adhesion, and the metabolic activity of hMSCs in } \\
\text { complex with fibrinogen }\end{array}$ & [103] \\
\hline & & $\begin{array}{l}\text { PEGDA/collagen } \\
\text { PEGDA/fibrinogen }\end{array}$ & $\begin{array}{c}\text { Enhancing the differentiation of human adipose-derived stem cells (hADSCs) } \\
\text { and cell proliferation and pluripotency of hMSCs }\end{array}$ & $\begin{array}{l}{[110]} \\
{[111]}\end{array}$ \\
\hline \multirow{7}{*}{ Covalent cross-linking } & \multirow[b]{2}{*}{ Cross-linking with XIII factor } & \multirow[b]{2}{*}{ Fibrin } & $\begin{array}{l}\text { Increasing cell adhesion and spreading in sheep lung mesenchymal cells and } \\
\text { tissue regeneration in vivo }\end{array}$ & [112] \\
\hline & & & $\begin{array}{l}\text { Sustaining the release of bone morphogenic protein (BMP2) and the } \\
\text { expression of osteogenic markers in preosteoblast cells; improving tissue } \\
\text { regeneration in vivo }\end{array}$ & [113] \\
\hline & \multirow[b]{2}{*}{ Photo cross-linking } & \multirow[b]{2}{*}{ Hyaluronic acid } & Increasing cell viability and tubular organization of HUVECs & [101] \\
\hline & & & $\begin{array}{l}\text { Improving the cell adhesion and proliferation of MSCs; expressing YAS } \\
\text { protein in encapsulated cells }\end{array}$ & [99] \\
\hline & Maleimide reaction & PEG & Increasing cell adhesion and proliferation in human cardiovascular cell types & [114] \\
\hline & Enzymatic cross-linking & Poloxamine & Enhancing the cell adhesion and proliferation of hMSCs and HUVECs & {$[100,115]$} \\
\hline & Cross-linking by radicals & Plasma immersion PA & Improving the cell adhesion and proliferation of human dermal fibroblast & [116] \\
\hline
\end{tabular}


Moreover, Fn can also be covalently linked to synthetic-material-based hydrogels. For example, maleimide-functionalized PEG can react with cysteine residues of Fn and form covalent bonds with sulfhydryl groups [114,118]. The resulting PEG-Fn, associated with PEG-heparin, formed a hydrogel that significantly enhanced the adhesion of cardiovascular cells to a greater extent than when PEG-RGD was used in place of PEG-Fn [114]. Other studies report Fn-covalent incorporation in Tetronic ${ }^{\circledR}$-tyramide polymer via a one-step enzymatic reaction with $\mathrm{H}_{2} \mathrm{O}_{2}$ and horseradish peroxidase (HRP) $[100,115]$. The cell adhesion and proliferation of hMSCs were remarkably influenced by the Fn concentration and covalent immobilization; at the highest concentration tested $(50 \mu \mathrm{g} / \mathrm{mL})$, mature F-actin fibers and higher cell proliferation were observed, whereas no improvement was observed when Fn was physically adsorbed on hydrogels [115]. Similar results were obtained in a PA hydrogel obtained by embedding radicals from plasma immersion ion implantation [116]. Fn was mixed into an acrylamide precursor prior to polymerization or coated on the surface of the formed hydrogel. The presence of radicals inside the hydrogels generated by plasma immersion is believed to covalently cross-link Fn to the hydrogel matrix. The researchers demonstrated significantly higher human dermal fibroblast adhesion and proliferation on both hydrogels functionalized with Fn compared to those on a bare hydrogel.

\subsection{Potential for the Use of Fn in Medical Applications}

The sections above present different state-of-the-art strategies developed to generate Fn implants that can be considered for potential medical applications. It is evident that, from synthetic or recombinant fragments to whole Fn purified from animal or human plasma, these strategies have biological potential for directing tissue responses and promoting repair in the human body.

Recently, the use of Fn-modified biomaterials in surgical applications has been reported in different studies, especially in animal models (from rodents to dogs) [119-122]. Some opportunities can also be explored for human applications, and the clinical use of Fn-modified biomaterials can now be seriously considered. However, in these cases, aspects beyond the biological tissular response benefits need to be considered, such as concerns about safety and regulatory affairs.

Synthetic or recombinant strategies using Fn fragments are powerful; however, as explained above, the use of whole animal or human Fn may represent a pertinent alternative for fully harnessing the potential of this molecule. With produced fragments, the issues of immunocompatibility and the risk of contamination are less prominent. Nevertheless, in the case of animal or human purified molecules, the control of the source and the origin of the material have to be carefully considered, and questions about quality assurance and regulatory affairs are central. For human medical applications, we can envision, as developed previously with platelet-rich plasma, the use of Fn purified from the patient themself. This approach necessitates some optimization of the purification process at the bedside. Allogenic xenogenic sources may also be considered; however, in that case, the perfect control of the purification and the analysis of the elimination of immunological markers and viruses would be essential.

\section{Conclusions}

Biomaterial bio-integration constitutes one of the main challenges in regenerative medicine, as it conditions the success of medical device implantation in the human body. Over the last few decades, several strategies have been developed to improve cell-material interactions, and in particular, biomaterial biofunctionalization with ECM proteins has received particular interest. Among these ECM proteins, Fn has caught the attention of researchers due to the presence of binding domains specific for cell integrins, heparin, and GFs. However, Fn is a very large and complex protein able to adopt different conformations, from a compact globular form in circulating fluids to an extended and fibrillar conformation at interfaces, which makes it difficult to handle. In this review, we focused 
on the descriptions of different strategies developed for Fn-material functionalization, from simple coatings at interfaces to complex Fn-enriched materials in bulk materials. Fn addition is not trivial, and the method of supplying the protein to a material, from simple physical coating or physical entrapment to covalent grafting, strongly affects the protein's dynamic conformation and, thus, bioactivity. The ideal choice of strategy highly depends on the material physico-chemical and surface properties. Despite this complexity, Fn functionalization is promising and presents numerous advantages for synergy with the properties of other molecules from the ECM or GFs.

Author Contributions: C.P.-D., A.G. and E.P. contributed equally to the writing of this review. A.G. and E.P. contributed equally to the supervision of the manuscript. All authors have read and agreed to the published version of the manuscript.

Funding: This research received no external funding.

Conflicts of Interest: The authors declare no conflict of interest.

\section{References}

1. Davis, H.E.; Leach, J.K. Designing Bioactive Delivery Systems for Tissue Regeneration. Ann. Biomed. Eng. 2011, 39, 1-13. [CrossRef] [PubMed]

2. Gabriel, D.; Dvir, T.; Kohane, D.S. Delivering Bioactive Molecules as Instructive Cues to Engineered Tissues. Expert. Opin. Drug Deliv. 2012, 9, 473-492. [CrossRef] [PubMed]

3. DeForest, C.A.; Anseth, K.S. Advances in Bioactive Hydrogels to Probe and Direct Cell Fate. Annu. Rev. Chem. Biomol. Eng. 2012, 3, 421-444. [CrossRef] [PubMed]

4. Montoya, C.; Du, Y.; Gianforcaro, A.L.; Orrego, S.; Yang, M.; Lelkes, P.I. On the Road to Smart Biomaterials for Bone Research: Definitions, Concepts, Advances, and Outlook. Bone Res. 2021, 9, 1-16. [CrossRef]

5. Ruoslahti, E. Fibronectin and its receptors. Annu. Rev. Biochem. 1988, 57, 375-413. [CrossRef]

6. Mosher, D.F. Physiology of Fibronectin. Annu. Rev. Med. 1984, 35, 561-575. [CrossRef]

7. Potts, J.R.; Campbell, I.D. Fibronectin Structure and Assembly. Curr. Opin. Cell Biol. 1994, 6, 648-655. [CrossRef]

8. Tsyguelnaia, I.; Doolittle, R.F. Presence of a Fibronectin Type III Domain in a Plant Protein. J. Mol. Evol. 1998, 46, 612-614. [CrossRef]

9. Yamada, K.M. Fibronectin Domains and Receptors. In Fibronection; Elsevier: Amsterdam, The Netherlands, 1989 ; pp. 47-121. ISBN 978-0-12-508470-3.

10. Kornblihtt, A.R.; Pesce, C.G.; Alonso, C.R.; Cramer, P.; Srebrow, A.; Werbajh, S.; Muro, A.F. The Fibronectin Gene as a Model for Splicing and Transcription Studies. FASEB J. 1996, 10, 248-257. [CrossRef]

11. Dickinson, C.D.; Veerapandian, B.; Dai, X.-P.; Hamlin, R.C.; Xuong, N.; Ruoslahti, E.; Ely, K.R. Crystal Structure of the Tenth Type III Cell Adhesion Module of Human Fibronectin. J. Mol. Biol. 1994, 236, 1079-1092. [CrossRef]

12. Williams, M.J.; Phan, I.; Harvey, T.S.; Rostagno, A.; Gold, L.I.; Campbell, I.D. Solution Structure of a Pair of Fibronectin Type 1 Modules with Fibrin Binding Activity. J. Mol. Biol. 1994, 235, 1302-1311. [CrossRef]

13. Sticht, H.; Pickford, A.R.; Potts, J.R.; Campbell, I.D. Solution Structure of the Glycosylated Second Type 2 Module of Fibronectin. J. Mol. Biol. 1998, 276, 177-187. [CrossRef]

14. Alexander, S.S.; Colonna, G.; Yamada, K.M.; Pastan, I.; Edelhoch, H. Molecular Properties of a Major Cell Surface Protein from Chick Embryo Fibroblasts. J. Biol. Chem. 1978, 253, 5820-5824. [CrossRef]

15. Alexander, S.S.; Colonna, G.; Edelhoch, H. The Structure and Stability of Human Plasma Cold-Insoluble Globulin. J. Biol. Chem. 1979, 254, 1501-1505. [CrossRef]

16. Mosesson, M.W.; Chen, A.B.; Huseby, R.M. The Cold-Insoluble Globulin of Human Plasma: Studies of Its Essential Structural Features. Biochim. Biophys. Acta (BBA)-Protein Struct. 1975, 386, 509-524. [CrossRef]

17. Koteliansky, V.E.; Glukhova, M.A.; Benjamin, M.V.; Smirnov, V.N.; Filimonov, V.V.; Zalite, O.M.; Venyaminov, S.Y. A Study of the Structure of Fibronectin. Eur. J. Biochem. 1981, 119, 619-624. [CrossRef]

18. Pelta, J.; Berry, H.; Fadda, G.C.; Pauthe, E.; Lairez, D. Statistical Conformation of Human Plasma Fibronectin. Biochemistry 2000, 39, 5146-5154. [CrossRef] [PubMed]

19. Baujard-Lamotte, L.; Noinville, S.; Goubard, F.; Marque, P.; Pauthe, E. Kinetics of Conformational Changes of Fibronectin Adsorbed onto Model Surfaces. Colloids Surf. B Biointerfaces 2008, 63, 129-137. [CrossRef]

20. Kornblihtt, A.R.; Umezawa, K.; Vibe-Pedersen, K.; Baralle, F.E. Primary Structure of Human Fibronectin: Differential Splicing May Generate at Least 10 Polypeptides from a Single Gene. EMBO J 1985, 4, 1755-1759. [CrossRef] [PubMed]

21. Dalby, M.J.; García, A.J.; Salmeron-Sanchez, M. Receptor Control in Mesenchymal Stem Cell Engineering. Nat. Rev. Mater. 2018, 3, 1-14. [CrossRef]

22. Martino, M.M.; Hubbell, J.A. The 12th-14th Type III Repeats of Fibronectin Function as a Highly Promiscuous Growth FactorBinding Domain. FASEB J. 2010, 24, 4711-4721. [CrossRef] 
23. Wilson, C.J.; Clegg, R.E.; Leavesley, D.I.; Pearcy, M.J. Mediation of Biomaterial-Cell Interactions by Adsorbed Proteins: A Review. Available online: https://www.liebertpub.com/doi/abs/10.1089/ten.2005.11.1 (accessed on 4 October 2021).

24. Davis, D.H.; Giannoulis, C.S.; Johnson, R.W.; Desai, T.A. Immobilization of RGD to $<111>$ Silicon Surfaces for Enhanced Cell Adhesion and Proliferation. Biomaterials 2002, 23, 4019-4027. [CrossRef]

25. Jin Yoon, J.; Ho Song, S.; Sung Lee, D.; Park, T.G. Immobilization of Cell Adhesive RGD Peptide onto the Surface of Highly Porous Biodegradable Polymer Scaffolds Fabricated by a Gas Foaming/Salt Leaching Method. Biomaterials 2004, 25, 5613-5620. [CrossRef] [PubMed]

26. García, A.J.; Schwarzbauer, J.E.; Boettiger, D. Distinct Activation States of A5 $\beta 1$ Integrin Show Differential Binding to RGD and Synergy Domains of Fibronectin. Biochemistry 2002, 41, 9063-9069. [CrossRef]

27. Kobayashi, H.; Ikacia, Y. Corneal Cell Adhesion and Proliferation on Hydrogel Sheets Bound with Cell-Adhesive Proteins. Curr. Eye Res. 1991, 10, 899-908. [CrossRef]

28. Kobayashi, H.; Ikada, Y.; Moritera, T.; Ogura, Y.; Honda, Y. Collagen-Immobilized Hydrogel as Material for Lamellar Keratoplasty. J. Appl. Biomater. 1991, 2, 261-267. [CrossRef]

29. Kobayashi, H.; Ikada, Y. Covalent Immobilization of Proteins on to the Surface of Poly(Vinyl Alcohol) Hydrogel. Biomaterials 1991, 12, 747-751. [CrossRef]

30. Nuttelman, C.R.; Mortisen, D.J.; Henry, S.M.; Anseth, K.S. Attachment of Fibronectin to Poly(Vinyl Alcohol) Hydrogels Promotes NIH3T3 Cell Adhesion, Proliferation, and Migration. J. Biomed. Mater. Res. 2001, 57, 217-223. [CrossRef]

31. Zajaczkowski, M.B.; Cukierman, E.; Galbraith, C.G.; Yamada, K.M. Cell-Matrix Adhesions on Poly(Vinyl Alcohol) Hydrogels. Tissue Eng. 2003, 9, 525-533. [CrossRef] [PubMed]

32. Grant, C.; Twigg, P.; Egan, A.; Moody, A.; Smith, A.; Eagland, D.; Crowther, N.; Britland, S. Poly(Vinyl Alcohol) Hydrogel as a Biocompatible Viscoelastic Mimetic for Articular Cartilage. Biotechnol. Prog. 2006, 22, 1400-1406. [CrossRef]

33. Millon, L.E.; Padavan, D.T.; Hamilton, A.M.; Boughner, D.R.; Wan, W. Exploring Cell Compatibility of a FibronectinFunctionalized Physically Crosslinked Poly(Vinyl Alcohol) Hydrogel. J. Biomed. Mater. Res. Part B Appl. Biomater. 2012, 100B, 1-10. [CrossRef]

34. Hynd, M.R.; Frampton, J.P.; Dowell-Mesfin, N.; Turner, J.N.; Shain, W. Directed Cell Growth on Protein-Functionalized Hydrogel Surfaces. J. Neurosci. Methods 2007, 162, 255-263. [CrossRef] [PubMed]

35. Abdeen, A.A.; Weiss, J.B.; Lee, J.; Kilian, K.A. Matrix Composition and Mechanics Direct Proangiogenic Signaling from Mesenchymal Stem Cells. Tissue Eng. Part A 2014, 20, 2737-2745. [CrossRef]

36. Lee, Y.B.; Lee, J.; Byun, H.; Ahmad, T.; Akashi, M.; Matsusaki, M.; Shin, H. One-Step Delivery of a Functional Multi-Layered Cell Sheet Using a Thermally Expandable Hydrogel with Controlled Presentation of Cell Adhesive Proteins. Biofabrication 2018, 10, 025001. [CrossRef] [PubMed]

37. Wacker, M.; Riedel, J.; Walles, H.; Scherner, M.; Awad, G.; Varghese, S.; Schürlein, S.; Garke, B.; Veluswamy, P.; Wippermann, J.; et al. Comparative Evaluation on Impacts of Fibronectin, Heparin-Chitosan, and Albumin Coating of Bacterial Nanocellulose SmallDiameter Vascular Grafts on Endothelialization In Vitro. Nanomaterials 2021, 11, 1952. [CrossRef] [PubMed]

38. Custódio, C.A.; Alves, C.M.; Reis, R.L.; Mano, J.F. Immobilization of Fibronectin in Chitosan Substrates Improves Cell Adhesion and Proliferation. J. Tissue Eng. Regen. Med. 2010, 4, 316-323. [CrossRef] [PubMed]

39. Rajangam, T.; An, S.S.A. Improved Fibronectin-Immobilized Fibrinogen Microthreads for the Attachment and Proliferation of Fibroblasts. Int. J. Nanomed. 2013, 8, 1037-1049. [CrossRef]

40. Warner, J.; Soman, P.; Zhu, W.; Tom, M.; Chen, S. Design and 3D Printing of Hydrogel Scaffolds with Fractal Geometries. ACS Biomater. Sci. Eng. 2016, 2, 1763-1770. [CrossRef]

41. Yamaki, K.; Harada, I.; Goto, M.; Cho, C.-S.; Akaike, T. Regulation of Cellular Morphology Using Temperature-Responsive Hydrogel for Integrin-Mediated Mechanical Force Stimulation. Biomaterials 2009, 30, 1421-1427. [CrossRef]

42. Schulte, A.; Alhusaini, Q.F.M.; Schönherr, H. Anodic Aluminum Oxide Nanopore Template-Assisted Fabrication of Nanostructured Poly(Vinyl Alcohol) Hydrogels for Cell Studies. ACS Appl. Bio. Mater. 2020, 3, 2419-2427. [CrossRef]

43. Shinohara, S.; Kihara, T.; Sakai, S.; Matsusaki, M.; Akashi, M.; Taya, M.; Miyake, J. Fabrication of in Vitro Three-Dimensional Multilayered Blood Vessel Model Using Human Endothelial and Smooth Muscle Cells and High-Strength PEG Hydrogel. J. Biosci. Bioeng. 2013, 116, 231-234. [CrossRef] [PubMed]

44. Wu, L.; Ferracci, G.; Wang, Y.; Fan, T.F.; Cho, N.-J.; Chow, P.K.H. Porcine Hepatocytes Culture on Biofunctionalized 3D Inverted Colloidal Crystal Scaffolds as an in Vitro Model for Predicting Drug Hepatotoxicity. RSC Adv. 2019, 9, 17995-18007. [CrossRef]

45. Sharma, R.I.; Snedeker, J.G. Biochemical and Biomechanical Gradients for Directed Bone Marrow Stromal Cell Differentiation toward Tendon and Bone. Biomaterials 2010, 31, 7695-7704. [CrossRef] [PubMed]

46. Stanton, A.E.; Tong, X.; Yang, F. Extracellular Matrix Type Modulates Mechanotransduction of Stem Cells. Acta Biomater. 2019, 96, 310-320. [CrossRef] [PubMed]

47. Xia, T.; Zhao, R.; Feng, F.; Yang, L. The Effect of Matrix Stiffness on Human Hepatocyte Migration and Function-An In Vitro Research. Polymers 2020, 12, 1903. [CrossRef]

48. Vallières, K.; Petitclerc, E.; Laroche, G. Covalent Grafting of Fibronectin onto Plasma-Treated PTFE: Influence of the Conjugation Strategy on Fibronectin Biological Activity. Macromol. Biosci. 2007, 7, 738-745. [CrossRef] [PubMed]

49. Vallières, K.; Chevallier, P.; Sarra-Bournet, C.; Turgeon, S.; Laroche, G. AFM Imaging of Immobilized Fibronectin: Does the Surface Conjugation Scheme Affect the Protein Orientation/Conformation? Langmuir 2007, 23, 9745-9751. [CrossRef] 
50. Ghadhab, S.; Bilem, I.; Guay-Bégin, A.-A.; Chevallier, P.; Auger, F.A.; Ruel, J.; Pauthe, E.; Laroche, G. Fibronectin Grafting to Enhance Skin Sealing around Transcutaneous Titanium Implant. J. Biomed. Mater. Res. Part A 2021. [CrossRef]

51. Vanslambrouck, S.; Chevallier, P.; Guay-Bégin, A.-A.; Laroche, G. Effect of Linking Arm Hydrophilic/Hydrophobic Nature, Length and End-Group on the Conformation and the RGD Accessibility of Surface-Immobilized Fibronectin. Mater. Sci. Eng. C 2020, 107, 110335. [CrossRef]

52. Zhang, Y.; Chai, C.; Jiang, X.S.; Teoh, S.H.; Leong, K.W. Fibronectin Immobilized by Covalent Conjugation or Physical Adsorption Shows Different Bioactivity on Aminated-PET. Mater. Sci. Eng. C 2007, 27, 213-219. [CrossRef]

53. Allen, L.T.; Tosetto, M.; Miller, I.S.; O'Connor, D.P.; Penney, S.C.; Lynch, I.; Keenan, A.K.; Pennington, S.R.; Dawson, K.A.; Gallagher, W.M. Surface-Induced Changes in Protein Adsorption and Implications for Cellular Phenotypic Responses to Surface Interaction. Biomaterials 2006, 27, 3096-3108. [CrossRef]

54. Barrias, C.C.; Martins, M.C.L.; Almeida-Porada, G.; Barbosa, M.A.; Granja, P.L. The Correlation between the Adsorption of Adhesive Proteins and Cell Behaviour on Hydroxyl-Methyl Mixed Self-Assembled Monolayers. Biomaterials 2009, 30, 307-316. [CrossRef]

55. Rabe, M.; Verdes, D.; Seeger, S. Understanding Protein Adsorption Phenomena at Solid Surfaces. Adv. Colloid Interface Sci. 2011, 162, 87-106. [CrossRef] [PubMed]

56. Pegueroles, M.; Aparicio, C.; Bosio, M.; Engel, E.; Gil, F.J.; Planell, J.A.; Altankov, G. Spatial Organization of Osteoblast Fibronectin Matrix on Titanium Surfaces: Effects of Roughness, Chemical Heterogeneity and Surface Energy. Acta Biomater. 2010, 6, 291-301. [CrossRef] [PubMed]

57. De Luca, A.C.; Zink, M.; Weidt, A.; Mayr, S.G.; Markaki, A.E. Effect of Microgrooved Surface Topography on Osteoblast Maturation and Protein Adsorption. J. Biomed. Mater. Res. A 2015, 103, 2689-2700. [CrossRef] [PubMed]

58. González-García, C.; Sousa, S.R.; Moratal, D.; Rico, P.; Salmerón-Sánchez, M. Effect of Nanoscale Topography on Fibronectin Adsorption, Focal Adhesion Size and Matrix Organisation. Colloids Surf. B Biointerfaces 2010, 77, 181-190. [CrossRef]

59. Grinnell, F.; Feld, M.K. Fibronectin Adsorption on Hydrophilic and Hydrophobic Surfaces Detected by Antibody Binding and Analyzed during Cell Adhesion in Serum-Containing Medium. J. Biol. Chem. 1982, 257, 4888-4893. [CrossRef]

60. Toworfe, G.K.; Composto, R.J.; Adams, C.S.; Shapiro, I.M.; Ducheyne, P. Fibronectin Adsorption on Surface-Activated Poly(Dimethylsiloxane) and Its Effect on Cellular Function. J. Biomed. Mater. Res. A 2004, 71, 449-461. [CrossRef]

61. Bergkvist, M.; Carlsson, J.; Oscarsson, S. Surface-Dependent Conformations of Human Plasma Fibronectin Adsorbed to Silica, Mica, and Hydrophobic Surfaces, Studied with Use of Atomic Force Microscopy. J. Biomed. Mater. Res. Part A 2003, 64A, 349-356. [CrossRef] [PubMed]

62. Keselowsky, B.G.; Collard, D.M.; García, A.J. Surface Chemistry Modulates Fibronectin Conformation and Directs Integrin Binding and Specificity to Control Cell Adhesion. J. Biomed. Mater. Res. Part A 2003, 66A, 247-259. [CrossRef]

63. Lin, M.; Wang, H.; Ruan, C.; Xing, J.; Wang, J.; Li, Y.; Wang, Y.; Luo, Y. Adsorption Force of Fibronectin on Various Surface Chemistries and Its Vital Role in Osteoblast Adhesion. Biomacromolecules 2015, 16, 973-984. [CrossRef] [PubMed]

64. Rico, P.; Hernández, J.C.R.; Moratal, D.; Altankov, G.; Pradas, M.M.; Salmerón-Sánchez, M. Substrate-Induced Assembly of Fibronectin into Networks: Influence of Surface Chemistry and Effect on Osteoblast Adhesion. Tissue Eng. Part A 2009, 15, 3271-3281. [CrossRef]

65. Salmerón-Sánchez, M.; Rico, P.; Moratal, D.; Lee, T.T.; Schwarzbauer, J.E.; García, A.J. Role of Material-Driven Fibronectin Fibrillogenesis in Cell Differentiation. Biomaterials 2011, 32, 2099-2105. [CrossRef]

66. Llopis-Hernández, V.; Cantini, M.; González-García, C.; Cheng, Z.A.; Yang, J.; Tsimbouri, P.M.; García, A.J.; Dalby, M.J.; Salmerón-Sánchez, M. Material-Driven Fibronectin Assembly for High-Efficiency Presentation of Growth Factors. Sci. Adv. 2016, 2, e1600188. [CrossRef] [PubMed]

67. Moulisová, V.; Gonzalez-García, C.; Cantini, M.; Rodrigo-Navarro, A.; Weaver, J.; Costell, M.; Sabater I Serra, R.; Dalby, M.J.; García, A.J.; Salmerón-Sánchez, M. Engineered Microenvironments for Synergistic VEGF-Integrin Signalling during Vascularization. Biomaterials 2017, 126, 61-74. [CrossRef]

68. Anderson, J.M.; Rodriguez, A.; Chang, D.T. Foreign body reaction to biomaterials. Semin Immunol. 2008, 20, 86-100. [CrossRef]

69. Shen, M.; Garcia, I.; Maier, R.V.; Horbett, T.A. Effects of Adsorbed Proteins and Surface Chemistry on Foreign Body Giant Cell Formation, Tumor Necrosis Factor Alpha Release and Procoagulant Activity of Monocytes. J. Biomed. Mater. Res. Part A 2004, 70A, 533-541. [CrossRef] [PubMed]

70. Gossart, A.; Gand, A.; Ollivier, V.; Boissière, M.; Santerre, J.P.; Letourneur, D.; Pauthe, E. Coating of Cobalt Chrome Substrates with Thin Films of Polar/Hydrophobic/Ionic Polyurethanes: Characterization and Interaction with Human Immunoglobulin G and Fibronectin. Colloids Surf. B Biointerfaces 2019, 179, 114-120. [CrossRef]

71. Keefe, A.D.; Pai, S.; Ellington, A. Aptamers as Therapeutics. Nat. Rev. Drug Discov. 2010, 9, 537-550. [CrossRef] [PubMed]

72. Parisi, L.; Galli, C.; Bianchera, A.; Lagonegro, P.; Elviri, L.; Smerieri, A.; Lumetti, S.; Manfredi, E.; Bettini, R.; Macaluso, G.M. Anti-Fibronectin Aptamers Improve the Colonization of Chitosan Films Modified with D-(+) Raffinose by Murine Osteoblastic Cells. J. Mater. Sci. Mater. Med. 2017, 28, 136. [CrossRef]

73. Parisi, L.; Toffoli, A.; Bianchi, M.G.; Bergonzi, C.; Bianchera, A.; Bettini, R.; Elviri, L.; Macaluso, G.M. Functional Fibronectin Adsorption on Aptamer-Doped Chitosan Modulates Cell Morphology by Integrin-Mediated Pathway. Materials 2019, 12, 812. [CrossRef] [PubMed] 
74. Montaño-Machado, V.; Chevallier, P.; Mantovani, D.; Pauthe, E. On the Potential for Fibronectin/Phosphorylcholine Coatings on PTFE Substrates to Jointly Modulate Endothelial Cell Adhesion and Hemocompatibility Properties. Biomatter 2015, 5, e979679. [CrossRef]

75. Li, G.; Yang, P.; Qin, W.; Maitz, M.F.; Zhou, S.; Huang, N. The Effect of Coimmobilizing Heparin and Fibronectin on Titanium on Hemocompatibility and Endothelialization. Biomaterials 2011, 32, 4691-4703. [CrossRef] [PubMed]

76. Sousa, S.R.; Lamghari, M.; Sampaio, P.; Moradas-Ferreira, P.; Barbosa, M.A. Osteoblast Adhesion and Morphology on TiO2 Depends on the Competitive Preadsorption of Albumin and Fibronectin. J. Biomed. Mater. Res. Part A 2008, 84A, 281-290. [CrossRef] [PubMed]

77. Zelzer, M.; Albutt, D.; Alexander, M.R.; Russell, N.A. The Role of Albumin and Fibronectin in the Adhesion of Fibroblasts to Plasma Polymer Surfaces. Plasma Process. Polym. 2012, 9, 149-156. [CrossRef]

78. Hindié, M.; Camand, E.; Agniel, R.; Carreiras, F.; Pauthe, E.; Van Tassel, P. Effects of Human Fibronectin and Human Serum Albumin Sequential Adsorption on Preosteoblastic Cell Adhesion. Biointerphases 2014, 9, 029008. [CrossRef]

79. Gribova, V.; Auzely-Velty, R.; Picart, C. Polyelectrolyte Multilayer Assemblies on Materials Surfaces: From Cell Adhesion to Tissue Engineering. Chem. Mater. 2012, 24, 854-869. [CrossRef]

80. Decher, G.; Hong, J.D.; Schmitt, J. Buildup of Ultrathin Multilayer Films by a Self-Assembly Process: III. Consecutively Alternating Adsorption of Anionic and Cationic Polyelectrolytes on Charged Surfaces. Thin Solid Film. 1992, 210-211, 831-835. [CrossRef]

81. Wu, C.; Aslan, S.; Gand, A.; Wolenski, J.S.; Pauthe, E.; Van Tassel, P.R. Porous Nanofilm Biomaterials Via Templated Layer-by-Layer Assembly. Adv. Funct. Mater. 2013, 23, 66-74. [CrossRef]

82. Gand, A.; Hindié, M.; Chacon, D.; Van Tassel, P.R.; Pauthe, E. Nanotemplated Polyelectrolyte Films as Porous Biomolecular Delivery Systems. Application to the Growth Factor BMP-2. Biomatter 2014, 4, e28823. [CrossRef]

83. Guan, B.; Wang, H.; Xu, R.; Zheng, G.; Yang, J.; Liu, Z.; Cao, M.; Wu, M.; Song, J.; Li, N.; et al. Establishing Antibacterial Multilayer Films on the Surface of Direct Metal Laser Sintered Titanium Primed with Phase-Transited Lysozyme. Sci. Rep. 2016, 6, 36408. [CrossRef]

84. Shi, Q.; Qian, Z.; Liu, D.; Liu, H. Surface Modification of Dental Titanium Implant by Layer-by-Layer Electrostatic Self-Assembly. Front. Physiol. 2017, 8, 574. [CrossRef]

85. Hartmann, H.; Krastev, R. Biofunctionalization of Surfaces Using Polyelectrolyte Multilayers. BioNanoMaterials 2017, 18. [CrossRef]

86. Ouni, O.A.; Subbiahdoss, G.; Scheberl, A.; Reimhult, E. DNA Polyelectrolyte Multilayer Coatings Are Antifouling and Promote Mammalian Cell Adhesion. Materials 2021, 14, 4596. [CrossRef]

87. Wittmer, C.R.; Phelps, J.A.; Saltzman, W.M.; Van Tassel, P.R. Fibronectin Terminated Multilayer Films: Protein Adsorption and Cell Attachment Studies. Biomaterials 2007, 28, 851-860. [CrossRef] [PubMed]

88. Ngankam, A.P.; Mao, G.; Van Tassel, P.R. Fibronectin Adsorption onto Polyelectrolyte Multilayer Films. Langmuir 2004, 20, 3362-3370. [CrossRef]

89. Kreke, M.R.; Badami, A.S.; Brady, J.B.; Akers, R.M.; Goldstein, A.S. Modulation of Protein Adsorption and Cell Adhesion by Poly(Allylamine Hydrochloride) Heparin Films. Biomaterials 2005, 26, 2975-2981. [CrossRef]

90. Li, M.; Mills, D.K.; Cui, T.; McShane, M.J. Cellular Response to Gelatin- and Fibronectin-Coated Multilayer Polyelectrolyte Nanofilms. IEEE Trans. NanoBioscience 2005, 4, 170-179. [CrossRef]

91. Reyes, D.R.; Hong, J.S.; Elliott, J.T.; Gaitan, M. Hybrid Cell Adhesive Material for Instant Dielectrophoretic Cell Trapping and Long-Term Cell Function Assessment. Available online: https://pubs.acs.org/doi/pdf/10.1021/la200762j (accessed on 20 October 2021).

92. Bhadriraju, K.; Hong, J.S.; Lund, S.P.; Reyes, D.R. Fibronectin in Layer-by-Layer Assembled Films Switches Tumor Cells between 2D and 3D Morphology. Available online: https://pubs.acs.org/doi/pdf/10.1021/acsbiomaterials.7b00608 (accessed on 18 October 2021).

93. Gand, A.; Tabuteau, M.; Chat, C.; Ladam, G.; Atmani, H.; Van Tassel, P.R.; Pauthe, E. Fibronectin-Based Multilayer Thin Films. Colloids Surf B Biointerfaces 2017, 156, 313-319. [CrossRef] [PubMed]

94. Mauquoy, S.; Dupont-Gillain, C. Combination of Collagen and Fibronectin to Design Biomimetic Interfaces: Do These Proteins Form Layer-by-Layer Assemblies? Colloids Surf. B Biointerfaces 2016, 147, 54-64. [CrossRef]

95. Kadowaki, K.; Matsusaki, M.; Akashi, M. Control of Cell Surface and Functions by Layer-by-Layer Nanofilms. Langmuir 2010, 26, 5670-5678. [CrossRef]

96. Matsuzawa, A.; Matsusaki, M.; Akashi, M. Effectiveness of Nanometer-Sized Extracellular Matrix Layer-by-Layer Assembled Films for a Cell Membrane Coating Protecting Cells from Physical Stress. Available online: https://pubs.acs.org/doi/pdf/10.1021/ la303459v (accessed on 19 October 2021).

97. Akther, F.; Little, P.; Li, Z.; Nguyen, N.-T.; Ta, H.T. Hydrogels as Artificial Matrices for Cell Seeding in Microfluidic Devices. RSC Adv. 2020, 10, 43682-43703. [CrossRef]

98. Ahearne, M. Introduction to Cell-Hydrogel Mechanosensing. Interface Focus 2014, 4, 20130038. [CrossRef] [PubMed]

99. Trujillo, S.; Vega, S.L.; Song, K.H.; Félix, A.S.; Dalby, M.J.; Burdick, J.A.; Salmeron-Sanchez, M. Engineered Full-Length FibronectinHyaluronic Acid Hydrogels for Stem Cell Engineering. Adv. Healthc. Mater. 2020, 9, 2000989. [CrossRef]

100. Jun, I.; Ahmad, T.; Bak, S.; Lee, J.-Y.; Kim, E.M.; Lee, J.; Lee, Y.B.; Jeong, H.; Jeon, H.; Shin, H. Spatially Assembled Bilayer Cell Sheets of Stem Cells and Endothelial Cells Using Thermosensitive Hydrogels for Therapeutic Angiogenesis. Adv. Healthc. Mater. 2017, 6, 1601340. [CrossRef] 
101. Seidlits, S.K.; Drinnan, C.T.; Petersen, R.R.; Shear, J.B.; Suggs, L.J.; Schmidt, C.E. Fibronectin-Hyaluronic Acid Composite Hydrogels for Three-Dimensional Endothelial Cell Culture. Acta Biomater. 2011, 7, 2401-2409. [CrossRef]

102. Gilmozzi, V.; Gentile, G.; Riekschnitz, D.A.; Von Troyer, M.; Lavdas, A.A.; Kerschbamer, E.; Weichenberger, C.X.; Rosato-Siri, M.D.; Casarosa, S.; Conti, L.; et al. Generation of HiPSC-Derived Functional Dopaminergic Neurons in Alginate-Based 3D Culture. Front. Cell Dev. Biol. 2021, 9, 2013. [CrossRef] [PubMed]

103. Karoubi, G.; Ormiston, M.L.; Stewart, D.J.; Courtman, D.W. Single-Cell Hydrogel Encapsulation for Enhanced Survival of Human Marrow Stromal Cells. Biomaterials 2009, 30, 5445-5455. [CrossRef] [PubMed]

104. Mosahebi, A.; Wiberg, M.; Terenghi, G. Addition of Fibronectin to Alginate Matrix Improves Peripheral Nerve Regeneration in Tissue-Engineered Conduits. Tissue Eng. 2003, 9, 209-218. [CrossRef] [PubMed]

105. Novikova, L.N.; Mosahebi, A.; Wiberg, M.; Terenghi, G.; Kellerth, J.-O.; Novikov, L.N. Alginate Hydrogel and Matrigel as Potential Cell Carriers for Neurotransplantation. J. Biomed. Mater. Res. Part A 2006, 77A, 242-252. [CrossRef]

106. Zhou, Y.; Qin, R.; Chen, T.; Zhang, K.; Gui, J. 3D Bioprinting Modified Autologous Matrix-Induced Chondrogenesis(AMIC) Technique for Repair of Cartilage Defects. Mater. Des. 2021, 203, 109621. [CrossRef]

107. Gonzalez-Perez, F.; Hernández, J.; Heimann, C.; Phillips, J.B.; Udina, E.; Navarro, X. Schwann Cells and Mesenchymal Stem Cells in Laminin- or Fibronectin-Aligned Matrices and Regeneration across a Critical Size Defect of $15 \mathrm{Mm}$ in the Rat Sciatic Nerve. J. Neurosurg. Spine 2017, 28, 109-118. [CrossRef] [PubMed]

108. Norris, E.G.; Dalecki, D.; Hocking, D.C. Acoustic Fabrication of Collagen-Fibronectin Composite Gels Accelerates Microtissue Formation. Appl. Sci. 2020, 10, 2907. [CrossRef] [PubMed]

109. Leite, M.L.; Soares, D.G.; Anovazzi, G.; Anselmi, C.; Hebling, J.; Costa, C.A. de S. Fibronectin-Loaded Collagen/Gelatin Hydrogel Is a Potent Signaling Biomaterial for Dental Pulp Regeneration. J. Endod. 2021, 47, 1110-1117. [CrossRef] [PubMed]

110. Nii, M.; Lai, J.H.; Keeney, M.; Han, L.-H.; Behn, A.; Imanbayev, G.; Yang, F. The Effects of Interactive Mechanical and Biochemical Niche Signaling on Osteogenic Differentiation of Adipose-Derived Stem Cells Using Combinatorial Hydrogels. Acta Biomater. 2013, 9, 5475-5483. [CrossRef] [PubMed]

111. Goldshmid, R.; Seliktar, D. Hydrogel Modulus Affects Proliferation Rate and Pluripotency of Human Mesenchymal Stem Cells Grown in Three-Dimensional Culture. ACS Biomater. Sci. Eng. 2017, 3, 3433-3446. [CrossRef] [PubMed]

112. Ingenito, E.P.; Sen, E.; Tsai, L.W.; Murthy, S.; Hoffman, A. Design and Testing of Biological Scaffolds for Delivering Reparative Cells to Target Sites in the Lung. J. Tissue Eng. Regen. Med. 2010, 4, 259-272. [CrossRef]

113. Ao, Q.; Wang, S.; He, Q.; Ten, H.; Oyama, K.; Ito, A.; He, J.; Javed, R.; Wang, A.; Matsuno, A. Fibrin Glue/Fibronectin/HeparinBased Delivery System of BMP2 Induces Osteogenesis in MC3T3-E1 Cells and Bone Formation in Rat Calvarial Critical-Sized Defects. ACS Appl. Mater. Interfaces 2020, 12, 13400-13410. [CrossRef]

114. Nie, T.; Akins, R.E.; Kiick, K.L. Production of Heparin-Containing Hydrogels for Modulating Cell Responses. Acta Biomater. 2009, 5, 865-875. [CrossRef] [PubMed]

115. Jun, I.; Lee, Y.B.; Choi, Y.S.; Engler, A.J.; Park, H.; Shin, H. Transfer Stamping of Human Mesenchymal Stem Cell Patches Using Thermally Expandable Hydrogels with Tunable Cell-Adhesive Properties. Biomaterials 2015, 54, 44-54. [CrossRef]

116. Walia, R.; Akhavan, B.; Kosobrodova, E.; Kondyurin, A.; Oveissi, F.; Naficy, S.; Yeo, G.C.; Hawker, M.; Kaplan, D.L.; Dehghani, F.; et al. Hydrogel-Solid Hybrid Materials for Biomedical Applications Enabled by Surface-Embedded Radicals. Adv. Funct. Mater. 2020, 30, 2004599. [CrossRef]

117. Okada, M.; Blombäck, B.; Chang, M.D.; Horowitz, B. Fibronectin and Fibrin Gel Structure. J. Biol. Chem. 1985, 260, 1811-1820. [CrossRef]

118. Robinson, K.G.; Nie, T.; Baldwin, A.D.; Yang, E.C.; Kiick, K.L.; Akins, R.E. Differential Effects of Substrate Modulus on Human Vascular Endothelial, Smooth Muscle, and Fibroblastic Cells. J. Biomed. Mater. Res. Part A 2012, 100A, 1356-1367. [CrossRef]

119. Chang, Y.-C.; Ho, K.-N.; Feng, S.-W.; Huang, H.-M.; Chang, C.-H.; Lin, C.-T.; Teng, N.-C.; Pan, Y.H.; Chang, W.-J. FibronectinGrafted Titanium Dental Implants: An In Vivo Study. BioMed Res. Int. 2016, 2016, e2414809. [CrossRef] [PubMed]

120. Agarwal, R.; González-García, C.; Torstrick, B.; Guldberg, R.E.; Salmerón-Sánchez, M.; García, A.J. Simple Coating with Fibronectin Fragment Enhances Stainless Steel Screw Osseointegration in Healthy and Osteoporotic Rats. Biomaterials 2015, 63, 137-145. [CrossRef] [PubMed]

121. Zhang, B.G.X.; Myers, D.E.; Wallace, G.G.; Brandt, M.; Choong, P.F.M. Bioactive Coatings for Orthopaedic Implants-Recent Trends in Development of Implant Coatings. Int. J. Mol. Sci. 2014, 15, 11878-11921. [CrossRef] [PubMed]

122. Assmann, A.; Struß, M.; Schiffer, F.; Heidelberg, F.; Munakata, H.; Timchenko, E.V.; Timchenko, P.E.; Kaufmann, T.; Huynh, K.; Sugimura, Y.; et al. Improvement of the in Vivo Cellular Repopulation of Decellularized Cardiovascular Tissues by a DetergentFree, Non-Proteolytic, Actin-Disassembling Regimen. J. Tissue Eng. Regen. Med. 2017, 11, 3530-3543. [CrossRef] 